\title{
Integrative identification of unexpected kinase-inhibitor interactions in the MAPK-mediated proliferation and differentiation of Mc3T3-E1 osteoblasts
}

\author{
Lei Zhao ${ }^{1,2}$, Qun Huang ${ }^{2}$, Shoujin Tian², Jianfei Ge'2, Hongyan Zhu ${ }^{3}$ and Qirong Dong ${ }^{1}$ \\ ${ }^{1}$ Department of Orthopedics, The Second Affiliated Hospital of Soochow University, Suzhou 215004, China \\ ${ }^{2}$ Department of Orthopedics, The First People's Hospital of Zhangjiagang City, Zhangjiagang 215600, China \\ ${ }^{3}$ Department of Translational Medicine Research and Development Center, The First People's Hospital of Zhangjiagang City, \\ Zhangjiagang 215600, China
}

\begin{abstract}
Kinase-targeted therapy is a new and promising approach to disease treatment. However, some kinase inhibitors have been observed to cause an off-target adverse risk for skeletal system by influencing the growth of osteoblasts. It is known that the proliferation and differentiation of osteoblasts are essentially regulated by MAPK signaling pathway, and many off-target events are considered to influence this pathway. Here, the unexpected MAPK-inhibitor interactions in mouse MC3T3-E1 osteoblastic cells were investigated in detail using an integrative protocol. With bioinformatics analysis we successfully profiled a systematic noncognate interaction spectrum for off-target kinase inhibitors against mouse MAPK kinases, from which 13 potential MAPK-inhibitor interactions were identified. The inhibitors Nilotinib, Dasatinib and Bosutinib were suggested as promising candidates; their cytotoxicity on MC3T3-E1 and inhibitory activity against MAPK kinase were tested at cellular and molecular levels, respectively. We also tested two known MAPK inhibitors SP600125 and SB203580 as positive controls. Consequently, the Dasatinib was found to have high off-target risk for unexpectedly targeting osteoblast MAPK signaling pathway.
\end{abstract}

Key words: Mitogen-activated protein kinase - Kinase inhibitor - Off-target - Unexpected interaction - Molecular modeling - Osteoblast - MC3T3-E1

\section{Introduction}

Mitogen-activated protein kinase (MAPK) signaling pathway plays a critical role in bone development and maintenance (Thouverey and Caverzasio 2015). It has been reported that the MAPKs regulate bone mass through influencing osteoblast proliferation and differentiation (Ge et al. 2007; Greenblatt et al. 2010). This finding takes on particular relevance given that a majority of the secreted ligands that regulate osteoblast activity appear to signal in whole or in part through MAPK pathway (Greenblatt et al. 2013). Thus, shifting the kinase activity of MAPK members in osteoblasts

Correspondence to: Qirong Dong, Department of Orthopedics, The Second Affiliated Hospital of Soochow University, Suzhou 215004, China

E-mail: dongqirong@suda.edu.cn can directly or indirectly influence bone formation and skeletal remodeling ( $\mathrm{Hu}$ et al. 2003; Rodríguez-Carballo et al. 2016). For example, the natural product Resveratrol has been reported to reduce prostaglandin E1-stimulated osteoprotegerin synthesis in osteoblasts by suppressing MAPK family kinase JNK (Yamamoto et al. 2015), while the cytokine Irisin can promote osteoblast proliferation and differentiation via activating the MAPK pathway (Qiao et al. 2016).

Kinase-targeted therapy with small-molecule inhibitors has been widely used as therapeutic strategy to treat a variety of diseases such as cancer, inflammation and neurological disorder (Bhullar et al. 2018), which, however, were frequently observed to cause osteopenia and osteoporosis by unexpectedly disrupting and suppressing osteoblast growth (Alemán et al. 2014). A typical case is known as cancer treatment-induced bone loss (CTIBL), a long-term complication of anti-neoplastic treatments that leads to a high 
fracture risk in oncologic patients (D'Oronzo et al. 2015). Previously, the untargeted kinase-inhibitor interactions in cancer signaling pathway have been successfully identified from kinase-targeted therapies (Meng et al. 2018). The ATPbinding site is highly conserved across the protein kinase family, and many ATP-completive inhibitors may not be able to well distinguish between the sites of different kinases, thus resulting in off-target side effects (Anastassiadis et al. 2011). The off-target effects on bone health have been found as the untargeted consequences of targeted therapies with kinase inhibition (Alemán et al. 2014).

Here, we hypothesize that one or more kinase members in the MAPK family could be targeted unexpectedly by certain noncognate kinase inhibitors to cause off-target skeletal effects on osteoblast-mediated bone formation. Although there probably is an association between the bone pathogenesis and unexpected kinase-inhibitor interactions in the MAPK signaling cascade of osteoblasts, the underlying molecular mechanism and biological implication still remain largely unexplored. In order to support our hypotheses and to iden- tify the unexpected interactions that may cause off-target toxicity in osteogenic tissue, we herein profiled a systematic interaction spectrum of MAPK kinases expressed in mouse MC3T3-E1 osteoblastic cells with small-molecule inhibitors with reported off-target effects on bone formation, by integrating bioinformatics analysis, cell-based and cell-free assays, from which several MAPK-inhibitor interactions that are potentially associated with the osteopenia-related events were identified.

\section{Materials and Methods}

\section{Kinase inhibitors with off-target effects on bone formation}

A total of 18 small-molecule protein kinase inhibitors that have been reported to have off-target side effects on bone formation at cellular, animal and clinical levels were collected in Table 1. These inhibitors are diverse in terms of their chemical structures, including quinoline, indole, imidazole,

Table 1. The 18 kinase inhibitors reported to have off-target effects on bone formation

\begin{tabular}{|c|c|c|c|c|c|}
\hline \multirow{2}{*}{ Inhibitor } & \multirow{2}{*}{$\begin{array}{l}\text { Chemical } \\
\text { structure }\end{array}$} & \multirow{2}{*}{$\begin{array}{l}\text { Cognate } \\
\text { target }\end{array}$} & \multirow{2}{*}{$\begin{array}{l}\text { Crystal } \\
\text { complex }^{\mathrm{a}}\end{array}$} & \multicolumn{2}{|r|}{ Off-target effect } \\
\hline & & & & Level & Description \\
\hline GSK1838705A & & $\begin{array}{c}\text { IGF-1R | INSR | } \\
\text { ALK }\end{array}$ & n.a. & cell & $\begin{array}{l}\text { suppress osteoclast viability with } \\
\text { a dose- and time-dependent } \\
\text { manner }^{1}\end{array}$ \\
\hline PF-04691502 & & $\mathrm{AKT} \mid \mathrm{PI} 3 \mathrm{~K}$ & 3ML9 & cell & $\begin{array}{l}\text { suppress osteoclast viability with } \\
\text { a dose- and time-dependent } \\
\text { manner } 1\end{array}$ \\
\hline Masitinib & & KIT & n.a. & cell & $\begin{array}{l}\text { suppress osteoclast viability with } \\
\text { a dose- and time-dependent } \\
\text { manner }^{1}\end{array}$ \\
\hline Pictilisib & & PI3K & 2WXP & cell & $\begin{array}{l}\text { suppress osteoclast viability with } \\
\text { a dose- and time-dependent } \\
\text { manner }^{1}\end{array}$ \\
\hline Foretinib & & MET | VEGFR & 3LQ8 & cell & $\begin{array}{l}\text { suppress the osteoclast viability } \\
\text { with a dose- and time-dependent } \\
\text { manner }^{1}\end{array}$ \\
\hline Lapatinib & & HER1 | HER2 & 1XKK & cell & $\begin{array}{l}\text { promote osteoclast proliferation in } \\
\text { low dose } \mathrm{e}^{1}\end{array}$ \\
\hline
\end{tabular}




\begin{tabular}{|c|c|c|c|c|c|}
\hline \multirow{2}{*}{ Inhibitor } & \multirow{2}{*}{$\begin{array}{l}\text { Chemical } \\
\text { structure }\end{array}$} & \multirow{2}{*}{$\begin{array}{l}\text { Cognate } \\
\text { target }\end{array}$} & \multirow{2}{*}{$\begin{array}{l}\text { Crystal } \\
\text { complex }^{\mathrm{a}}\end{array}$} & \multicolumn{2}{|r|}{ Off-target effect } \\
\hline & & & & Level & Description \\
\hline Erlotinib & & EGFR & $1 \mathrm{M} 17$ & cell & $\begin{array}{l}\text { promote osteoclast proliferation in } \\
\text { low dose } \mathrm{e}^{1}\end{array}$ \\
\hline Imatinib & & BCR-ABL & $2 \mathrm{HYY}$ & clinical & alter bone and mineral metabolism ${ }^{2}$ \\
\hline Nilotinib & & BCR-ABL & $3 \mathrm{CS} 9$ & cell & decrease osteoclast development ${ }^{3}$ \\
\hline Dasatinib & & $\operatorname{Src} \mid \mathrm{Abl}$ & 3G5D & animal & dysregulate bone remodeling ${ }^{4}$ \\
\hline Sunitinib & & $\begin{array}{l}\text { PDGFR | VEGFR } \\
\mid \text { c-KIT }\end{array}$ & $3 \mathrm{G} 0 \mathrm{E}$ & clinical & $\begin{array}{l}\text { amplify the inhibition of bone } \\
\text { remodeling }\end{array}$ \\
\hline Bosutinib & & $\operatorname{Src} \mid \mathrm{Abl}$ & $4 \mathrm{MXO}$ & animal & $\begin{array}{l}\text { exhibit a minor adverse effect on } \\
\text { growing skeleton } 6\end{array}$ \\
\hline Cabozantinib & & MET | VEGFR & n.a. & cell & $\begin{array}{l}\text { have a dose-dependent biphasic } \\
\text { effect on osteoblast activity }\end{array}$ \\
\hline SYN1143 & & c-Met & n.a. & animal & $\begin{array}{l}\text { potentiate the differentiation of } \\
\text { precursor cells to osteoblasts }\end{array}$ \\
\hline SGX523 & & c-Met & $3 \mathrm{DKF}$ & animal & $\begin{array}{l}\text { potentiate the differentiation of } \\
\text { precursor cells to osteoblasts }{ }^{8}\end{array}$ \\
\hline Silmitasertib & & CK2 & 3NGA & cell & $\begin{array}{l}\text { enhance the BMP2-induced } \\
\text { osteoblast differentiation }\end{array}$ \\
\hline Dovitinib & & FGFR |c-Kit & $5 \mathrm{~A} 46$ & cell & $\begin{array}{l}\text { enhance the BMP2-induced } \\
\text { osteoblast differentiation }^{10}\end{array}$ \\
\hline AG-1295 & & PDGFR & n.a. & cell & $\begin{array}{l}\text { promote the osteogenic } \\
\text { differentiation of pre-osteoblastic } \\
\text { cells }{ }^{11}\end{array}$ \\
\hline
\end{tabular}

\footnotetext{
a the crystal complex structure is formed by kinase inhibitor with its cognate target; ${ }^{1}$ Bao et al. $2013 ;{ }^{2}$ Berman et al. 2016; ${ }^{3}$ O'Sullivan et al. 2011; ${ }^{4}$ Vandyke et al. 2010; ${ }^{5}$ Brunello et al. 2009; ${ }^{6}$ Tauer et al. $2013 ;{ }^{7}$ Dai et al. 2014; ${ }^{8}$ Kim et al. 2017; ${ }^{9}$ Son et al. $2013 ;{ }^{10}$ Lee et al. 2016; ${ }^{11}$ Zhang et al. 2012; n.a., not available.
} 
carboxamide, quinoxaline, etc; they are also diverse in terms of their cognate kinases, such as the sophisticated targets Src, EGFR, VEGFR and BCR-ABL. Some inhibitors (e.g. Imatinib) were found to have a long-term adverse effects on the mineral metabolism and bone mass of administrated patients (Berman et al. 2006), while some others (e.g. Dasatinib) were observed to dysregulate bone remodeling through inhibition of osteoclasts in vitro or in vivo (Vandyke et al. 2010). In particular, Bao and co-workers have performed a systematic kinase inhibitor screen against murine osteoblastic cell line and identified a number of candidates with potency to suppress cell viability in a dose- and time-dependent manner, although few compounds were observed to promote the cell proliferation at a very low concentration (Bao et al. 2013). These inhibitor compounds were also compiled here.

\section{Conventional mouse MAPK kinases}

The mouse MAPK family members can be classified into conventional and atypical kinases, which have distinct regulation and function. Only the conventional MAPKs are involved in the proliferation and differentiation of osteoblasts, which contains 10 kinases, namely extracellular signal-regulated kinase 1, 2 and 5 (Erk1/2/5), p38 isoforms $(\mathrm{p} 38 \alpha / \beta / \gamma / \delta)$ and $\mathrm{c}$-Jun $\mathrm{N}$-terminal kinases $1-3$ (Jnk1/2/3) (Cargnello and Roux 2011), which are the central components of the MAPK signaling cascade and share a similar kinase domain at $\mathrm{N}$-terminus but possess different additional portions at C-terminus.

In the 10 mouse MAPK kinases only p38 $\alpha$ is currently available to its crystal structure in the protein data bank (PDB) database (Berman et al. 2000). Here, we performed BLAST sequence search (Altschul et al. 1990) against the PDB database to identify homologous protein crystal templates for other 9 kinases. As can be seen in Table 2, the identified homologous templates are all human or rat MAPK counterparts, which have a very high sequence identity with the mouse kinases. In particular, the two mouse Erk2 and Jnk1 kinase domains have fully identical sequences (100\%) with that of human Erk2 and Jnk1 kinase domains, respectively; their structures would also be consistent. Considering the very high identity between other 6 mouse MAPK kinases and their homologous templates (>90\%), we herein did not adopt the widely used homology modeling technique (Marti-Renom et al. 2000) to build the mouse kinase structures. Instead, virtual residue mutagenesis (VRM) and statistical modeling (Zhou et al. 2013ab) were carried out to computationally mutate homologous protein templates to the three-dimensional structures of mouse kinases (except p38a as well as Erk2 and Jnk1). Here, the VRM was performed using BetaSCPWeb server (Ryu et al. 2016).

\section{Building MAPK-inhibitor complex structures}

The complex structures of 18 off-target inhibitors with 10 MAPK kinases were computationally modeled by either inhibitor grafting or molecular docking. Here, a total of 13 kinase inhibitors in Table 1 are available to their cocrystallized complex structures with partner kinases. Therefore, we can graft their binding mode from the ATP-binding site of partner kinases to the ATP-binding site of MAPK kinases. This procedure can be seen in Figure 1. The MAPK kinase is superposed onto the crystal structure of partner kinaseinhibitor complex to obtain a superposed system of partner kinase-inhibitor-MAPK kinase and then the partner kinase was removed from the superposed system to generate the

Table 2. The 10 conventional MAPK kinases expressed in mouse osteoblasts

\begin{tabular}{|c|c|c|c|c|c|c|c|}
\hline \multirow{3}{*}{ MAPK kinase } & \multirow{3}{*}{ UniProt $^{\mathrm{a}}$} & \multirow{3}{*}{ Specificity ${ }^{\mathrm{b}}$} & \multirow{3}{*}{ Kinase domain } & \multicolumn{4}{|c|}{ Structure } \\
\hline & & & & \multirow{2}{*}{$\mathrm{PDB}^{\mathrm{C}}$} & \multicolumn{3}{|c|}{ Homologous template $^{\mathrm{d}}$} \\
\hline & & & & & Protein & Identity & PDB \\
\hline MAPK3 Erk1 & Q63844 & Ser/Thr & residues $43-331$ & n.a. & human Erk1 & $99 \%$ & $2 \mathrm{ZOQ}$ \\
\hline MAPK1 Erk2 & P63085 & Ser/Thr & residues $23-311$ & n.a. & rat Erk2 & $100 \%$ & $1 \mathrm{ERK}$ \\
\hline MAPK7 Erk5 & Q9WVS8 & Ser/Thr & residues $55-347$ & n.a. & human Erk5 & $99 \%$ & $5 \mathrm{BYZ}$ \\
\hline MAPK14 p38a & P47811 & Ser/Thr & residues $24-308$ & $5 \mathrm{LAR}$ & - & - & - \\
\hline MAPK11 p38 $\beta$ & Q9WUI1 & Ser/Thr & residues $24-308$ & n.a. & human $\mathrm{p} 38 \beta$ & $99 \%$ & $3 \mathrm{GP0}$ \\
\hline MAPK12 p38 $\gamma$ & O08911 & Ser/Thr & residues $27-311$ & n.a. & human p38 & $93 \%$ & 1CM8 \\
\hline MAPK13 p38ס & Q9Z1B7 & Ser/Thr & residues $25-308$ & n.a. & human $\mathrm{p} 38 \delta$ & $92 \%$ & $3 \mathrm{COI}$ \\
\hline MAPK8 Jnk1 & Q91Y86 & Ser/Thr & residues $26-321$ & n.a. & human Jnk1 & $100 \%$ & 4QTD \\
\hline MAPK9 Jnk2 & Q9WTU6 & Ser/Thr & residues $26-321$ & n.a. & human Jnk2 & $96 \%$ & $3 \mathrm{E} 7 \mathrm{O}$ \\
\hline MAPK10 Jnk3 & Q61831 & Ser/Thr & residues 64-359 & n.a. & human Jnk3 & $99 \%$ & $1 J N K$ \\
\hline
\end{tabular}

${ }^{a}$ the accession ID of kinase's protein sequence in the UniProt database UniProt 2015; ${ }^{b}$ kinase's substrate specificity; ${ }^{c}$ n.a., not available;

$\mathrm{d}$ the crystal structure template of homologous protein used to model the mouse MAPK kinase domain structure. 


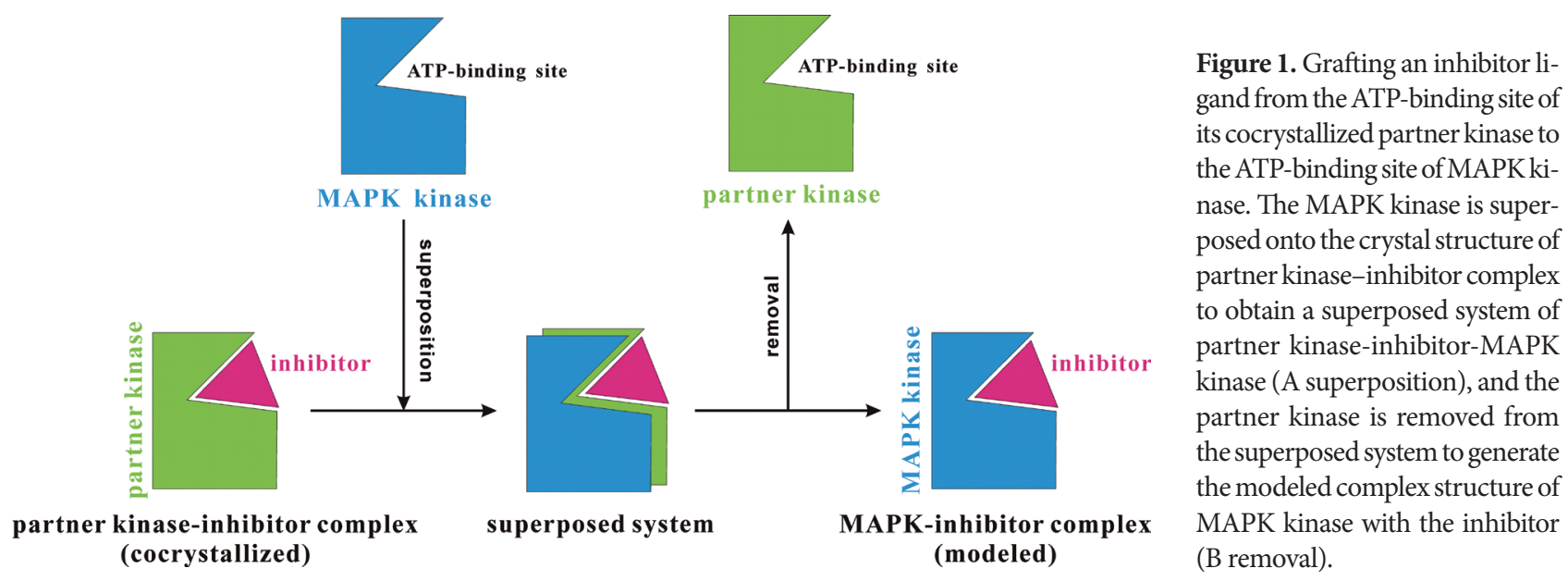

modeled complex structure of MAPK kinase with the inhibitor. Previously, the grafting strategy has been successfully applied to structural modeling of the complex systems of mTOR and HER2 kinase with small-molecule compounds and phospholipase A2 with peptide ligands (Cui et al. 2015; Zhan et al. 2015; Shen et al. 2016). For other 5 kinase inhibitors in Table 1, molecular docking calculations were used to predict their binding mode to MAPK kinases. The atoms of kinases and inhibitors were assigned with Kollman and Gasteiger partial charges, respectively. In docking procedure, the AutoDock Tools was employed to set the center and size of grid boxes covering the kinase's active site. The docking calculations were performed with AutoDock4 (Morris et al. 2009), which implemented Lamarckian genetic algorithm (LGA) to explore ligand conformational space in the active site of kinase receptor.

\section{Dynamics simulation and energetics analysis}

Through the inhibitor grafting and molecular docking a total of 180 MAPK-inhibitor complexes were obtained, which correspond to the systematic combination between 10 MAPK kinases and 18 off-target inhibitors. These complexes were subjected to molecular dynamics (MD) simulations implemented with AMBER14 software (Case et al. 2015). Inhibitor ligands were described with general AMBER force field (GAFF) (Wang et al. 2004), and their atomic charges were generated by using restrained electrostatic potential (RESP) fitting technique (Bayly et al. 1993). All the complex systems were immersed in a truncated octahedral box full of TIP3P water molecules and $\mathrm{Na}^{+}$ions were added to keep the systems electroneutrality (Bai et al. 2017). Subsequently, the systems were heated from 0 to $300 \mathrm{~K}$ over 100 ps and 5 -ns production simulations were carried in an isobaric-isothermal (NPT) ensemble with periodic boundary conditions (Zhou et al. 2016). The hydrogen atoms were constrained by performing the SHAKE method (Ryckaert et al. 1977) and time step was set to $2 \mathrm{fs}$. Long-range electrostatic forces were treated with particle-mesh Ewald (PME) (Darden et al. 1993) and nonbonded cutoff was set to $10 \AA$ (Yang et al. 2015a, 2016).

During the production phase snapshots were saved every 50 ps, which were then employed to calculate the binding affinity score $\Delta G$ by using molecular mechanics-Poisson Boltzmann/surface area (MM-PB/SA) method (Yang et al. 2015b):

$$
\begin{aligned}
& \Delta G=G_{\text {complex }}-\left(G_{\text {kinase }}+G_{\text {inhibitor }}\right)=\Delta E_{\text {interaction }}+ \\
& +\Delta D_{\text {desolvation }}
\end{aligned}
$$

where $\Delta E_{\text {interaction }}$ is the intermolecular interaction energy between kinase and inhibitor which includes electrostatic and van der Waals potentials and was described using AMBER molecular force field, and $\Delta G_{\text {desolvation }}$ is the desolvation effect upon kinase-inhibitor binding, which was computed by numerical solution of nonlinear PoissonBoltzmann equation (for polar contribution) and surface area model (for nonpolar contribution) (Yu et al. 2014; Zhou et al. 2018).

\section{Experimental part}

The potency of compounds Nilotinib, Dasatinib, Bosutinib, SP600125 (pan-JNK inhibitor) and SB203580 (pan-p38 inhibitor) on murine osteoblasts was investigated using cell viability assays (Mackay et al. 1999; Karahashi et al. 2000). The mouse MC3T3-E1 osteoblastic cell line Subclone 4 were cultured and expanded in basal medium containing in DMEM with $10 \%$ fetal calf serum and $5 \% \mathrm{CO}_{2}$ at $37^{\circ} \mathrm{C}$. The cells were seeded in a 96 well plate at $1 \times 10^{4}$ cells per well and treated with serial diluted compounds at different concentrations. Cell proliferation rate was measured using 
an amicroplate reader. The percentage of viable cells was calculated according to the following equation:

Viability $(\%)=\left(A_{\text {inhibitor }}-A_{\text {medium }}\right) /$

$/\left(A_{\text {control }}-A_{\text {medium }}\right) \times 100 \%$

where the $A_{\text {inhibitor }} A_{\text {control }}$ and $A_{\text {medium }}$ are the absorbance of cells treated with inhibitor, control and medium, respectively.
The activity of Dasatinib, SB203580 (positive control) and Bosutinib (negative control) against p38a kinase was determined using kinase inhibition assays (Lali et al. 2000; Hove et al. 2002). Kinase proteins were incubated in a buffer containing $50 \mathrm{mM}$ Tris- $\mathrm{HCl}, \mathrm{pH}$ 7.5, $1 \mathrm{mM}$ EDTA, $10 \mathrm{mM}$ $\mathrm{NaF}, 0.5 \mathrm{mM} \mathrm{Na}_{3} \mathrm{VO}_{4}, 0.1 \%$ Triton $\mathrm{X}-100,5 \mathrm{mM}$ sodium pyrophosphate as well as $1 \mu \mathrm{Ci}\left[\gamma^{-32} \mathrm{P}\right] \mathrm{ATP}$ and $0.5 \mathrm{mM}$ ATF-2 as substrate. Compounds were mixed with the reaction buffer and incubated for $20 \mathrm{~min}$ at room temperature,

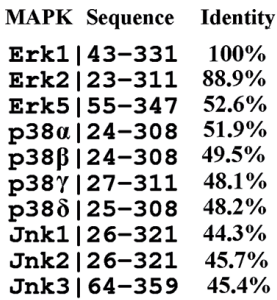

Erk1|43-331 $100 \%$ Erk2|23-311 $88.9 \%$ Erk5 $55-347 \quad 52.6 \%$ p $38 \alpha \mid 24-308 \quad 51.9 \%$ p38ß|24-308 $\quad 49.5 \%$ (2) $38 \%$ p $38 \gamma \mid 27-311 \quad 48.1 \%$ p38 $\delta \mid 25-308 \quad 48.2 \%$ Jnk1|26-321 $44.3 \%$ Jnk2|26-321 $45.7 \%$ Jnk3| $64-359 \quad 45.4 \%$

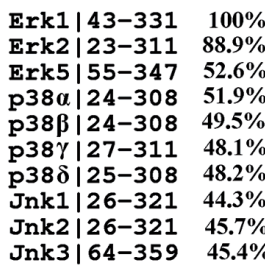

Erk1|43-331 $100 \%$ Erk2|23-311 $88.9 \%$ Erk5 $\mid 55-347 \quad 52.6 \%$ p38 $24-308 \quad 51.9 \%$ $38 \beta \mid 24-308 \quad 49.5 \%$ p $38 \beta \mid 24-308 \quad 49.5 \%$ p38 $\gamma \mid 27-311 \quad 48.1 \%$ p38 $\mid 25-308 \quad 48.2 \%$ Jnk1|26-321 $44.3 \%$ Jnk2|26-321 $45.7 \%$ Jnk3|64-359 $45.4 \%$ Erk1|43-331 $100 \%$

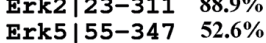
\begin{tabular}{l|ll} 
Erk5|55-347 & $\mathbf{5 2 . 6 \%}$ \\
p38a|24-308 & $\mathbf{5 1 . 9} \%$
\end{tabular}

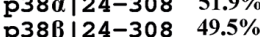
\begin{tabular}{ll|l} 
p38及|24-308 & $49.5 \%$ \\
p38 $\gamma \mid 27-311$ & $48.1 \%$
\end{tabular} p38 $\gamma \mid 27-311 \quad 48.1 \%$ Jnk1|26-321 44.3\% Jnk2 |26-321 45.7\% Jnk3|64-359 45.4\%

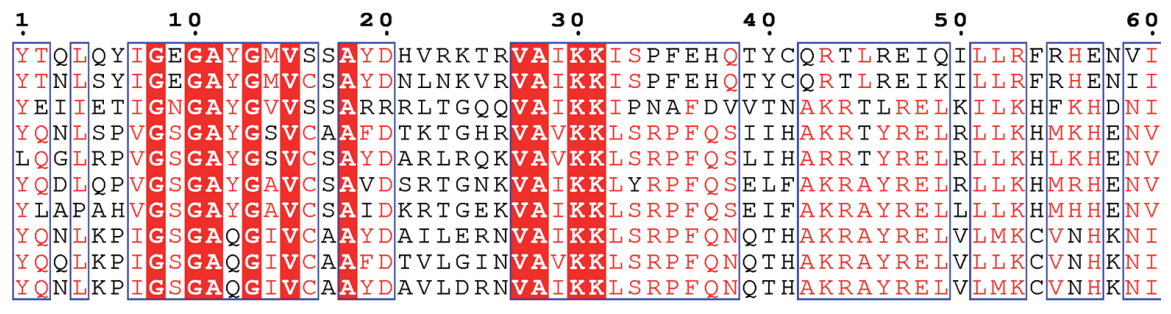

70

80

90

100

110

120

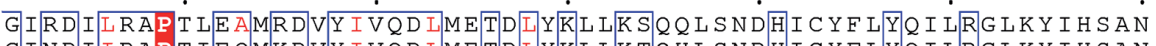
G I N D I I R A P T I E Q M K D V Y Y I VQ D L M E T D L Y K L L K T Q I A I K D I L KP T V P Y G E F R S SYVVLDL ME S D L H Q I I H S S QP L T L E HVR Y F L Y Q L L R G L K YMH

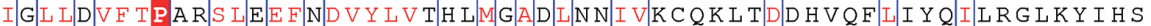
IGLIDVFTPATS IEDFSEVYLVTTLMGADINNIVIKCQALSDEHVQF LVYQLLRG LKY I HS

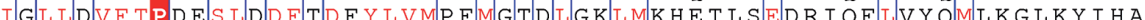
I DVYIVMEL I G L L N N V T T P Q K S L E E E E I S L L N V F T P Q K T L E E E $Q$ Q D V Y L VM E L M D A N L C Q V I H ME L D H E RM S Y L I Y Q M L C G I K H L H S A

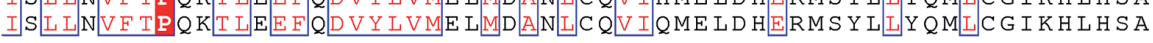

130

140

150

160

170

180

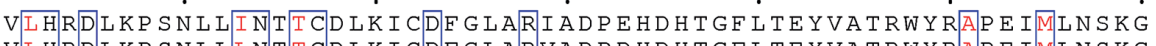

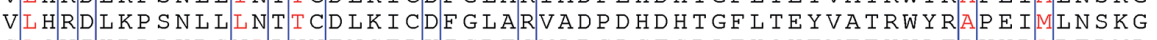
SA AVI HRDLKP S N L L VNENCELK I GDF GMARGLCTSPAEHQYFMTEYVATR WYRA P E LML AD I I R D LKP S N I AVNED CELKILDF G IARH T D EMT GYVA TRWYRAPE IMLNWMHYNQT A G I I R D LKP SNVAVNE D CELRILDFGIARQADE EMTGYVATRWYRAPE IMLNWMHYNT A GVI I RDLKPGN I AVNEDCELKILDFG ARQADSEMTGYVVTRWYRAPEVIINWMRYTQT A G

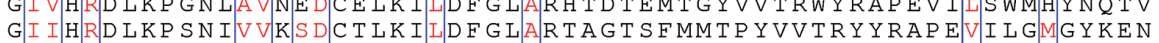

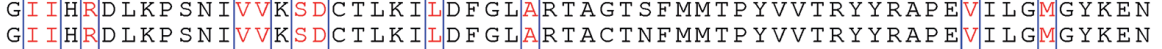

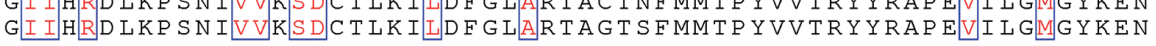

190

200

210

220

230

240

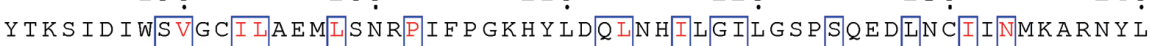
Y TKS I D I W.S V G C I L A E M I S NRP I F P GKHY L D Q L N H I L G I L G S P S Q E D L N C I I N L K A R N Y L

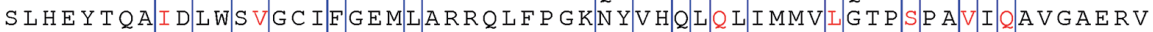
VDIWSVGCTMAETITGRTIFPGTDHIDOLKI I RIVGTPGAEITKKISSESARNYIOSIA DDI

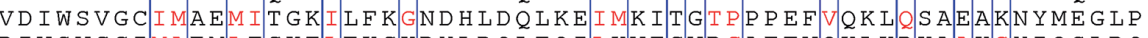
D I W S V G C I VDLW S V G C I M G E M V C H K VDIWSVGCIMAEMVLHKVILFP GRDY I QWNKVI E Q I G TP S A E F MKK L Q P TVVR Y Y V NRPK

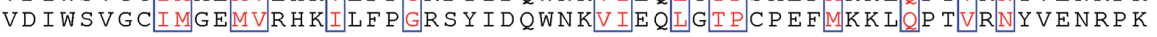

250

260

270

280

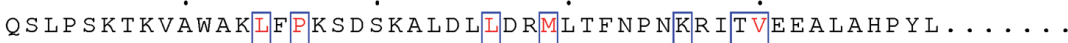

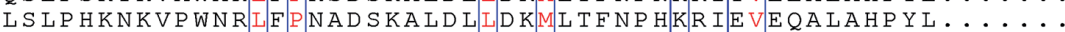
RAYIQSLPPRQPVPWETVYPGADROALSILGRMLRFEPSARISAAAALRHPFL . . .

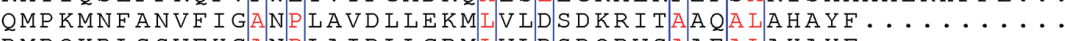

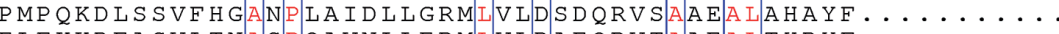

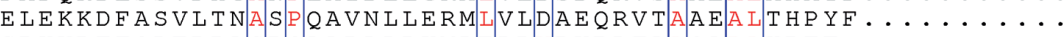

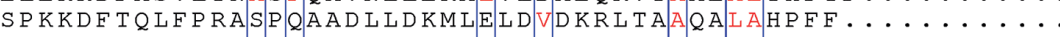
YAGYSFEKLEPDVIF P ADSEHNKLKASQARDLLSKMLVIDASKRISVDEALQHPY I YP G I KF E E LF P DWIF P SE SERDK I KTS QARD L L S KMLVI D P D R I SVDEA LRHPY I YA G T F P K L P D S I F A S EHNKLKASQARDLLSKMLVIDPVKRISVDDALQHPYI

Figure 2. Multiple sequence alignment between the primary sequences of 10 mouse MAPK kinase domains (Erk1, Erk2, Erk5, p38a, p38ß, p38 $\gamma$, p38 , Jnk1, Jnk2 and Jnk3). The alignment was carried out using ESPript program (Gouet et al. 2003). 
and then transferred onto a phosphocellulose piece. The piece was washed three times in phosphoric acid then in acetone at room temperature and $\gamma-{ }^{32} \mathrm{P}$ incorporation was then measured by scintillation counting.

\section{Results and Discussion}

\section{Homology analysis and grafting testing}

The primary sequences of 10 mouse MAPK kinase domains

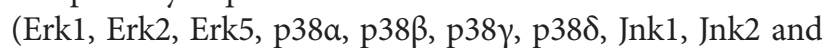
Jnk3) were retrieved from the UniProt database (UniProt 2015), and their sequence homology was analyzed using multiple sequence alignment implemented with ESPript program (Gouet et al. 2003). As can be seen in Figure 2, the alignment revealed a high consensus between these kinases, with sequence identity $>30 \%$ - the lower threshold for homologous proteins (Geourjon et al. 2001). As compared to C-terminus, the $\mathrm{N}$-terminus exhibits a larger conservation across the kinase family, as the conserved N-terminal section of kinases contains functional C-lobe and ATP-binding site. In addition, the 10 MAPK kinases can be divided into three subgroups, that is, Erk, p38 and Jnk; the kinases in the same subgroup are highly homologous to each other (identity $>60 \%$ ). This is expected since a subgroup represents a panel of evolutionally conserved proteins that possess a very similar function. For example, the Erk subgroup consists of three MAPK kinases, i.e. Erk1, Erk2 and Erk5. An 88.9\% sequence identity between Erk1 and Erk2 suggested that the two kinases are highly similar, displaying the same subcellular localization and sharing common activators and substrates (Lefloch et al. 2008). In contrast, the lower sequence identity (52.6\%) of Erk5 indicates a different function of this kinase in cardiovascular development and neural differentiation (Nishimoto and Nishida 2006).

According to above analysis the MAPK kinases are homologous in sequence, structure and function. In particular, the ATP-binding site is highly conversed across the kinase family. Therefore, it is readily supposed that, if an ATP-completive inhibitor can target different kinases, the inhibitor would adopt similar binding mode to interact with the kinases' ATP-binding sites. Previously, a systematic analysis of kinase-inhibitor crystal structure data deposited in the PDB database (Berman et al. 2000) also supported the supposition, although there are few exceptions (De Moliner et al. 2003; Vulpetti and Pevarello 2005). Here, three off-target inhibitors, namely, Dasatinib, Imatinib and Nilotinib, were used to test the reliability of inhibitor grafting strategy. The Dasatinib has crystal complex structure with p38a (PDB: 3lfa), which was also cocrystallized with its 11 partner kinases, including Abl (PDB: 2gqg), Arg (PDB: 4xli), Bmx (PDB: 3sxr), EphA2 (PDB: 5i9y), EphA4 (PDB: 2y6o), Lyn (PDB: 2zva), Mst3 (PDB: 4qms), Myt1 (PDB: 5vcv), Ptk6 (PDB: 5h2u), Src (PDB: 3g5d) and Stk10 (PDB: 5owr). We grafted the binding modes of Dasatinib ligand from these partner kinases to the ATP-binding site of p38a and then compared with its crystal binding mode in the site. Similarly, the cocrystallized and grafted binding modes of Imatinib and Nilotinib were also compared in an analogous way. As can be seen in Figure 3, all

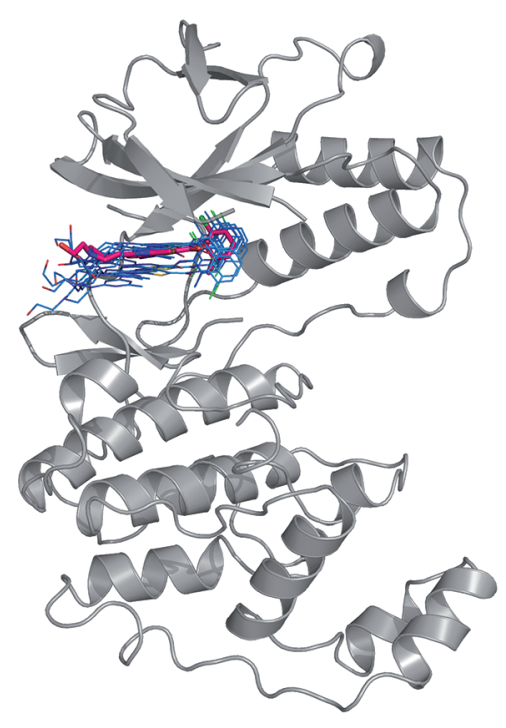

p38 $\alpha$-Dasatinib system

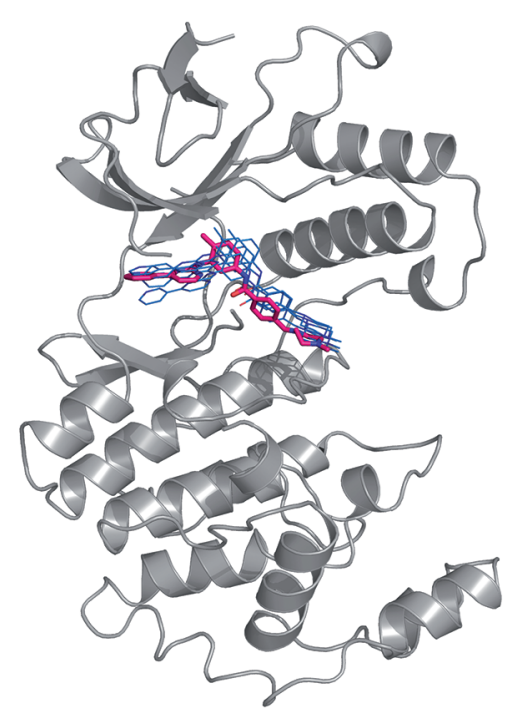

p38 $\alpha$-Imatinib system

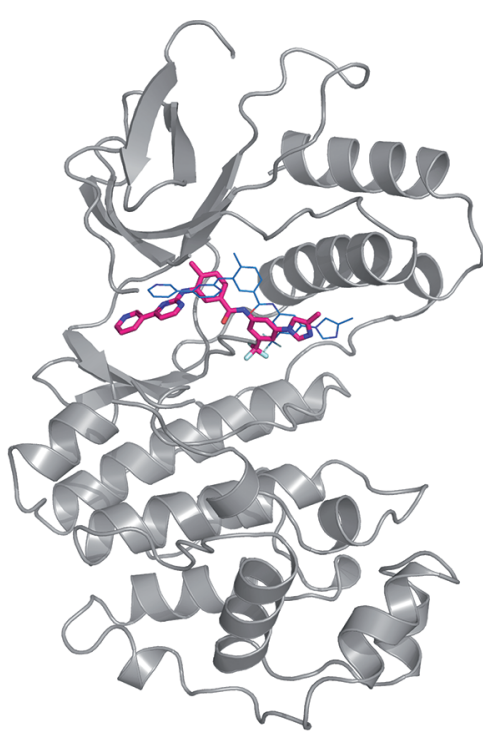

p38 $\beta$-Nilotinib system

Figure 3. Comparison between the cocrystallized binding mode and grafted binding modes of inhibitors Dasatinib (A), Imatinib (B) and Nilotinib (C) to MAPK kinases. The multiple grafted binding modes were generated based on the crystal complexes of the inhibitors with their different partner kinases. 
the three inhibitor ligands exhibits an extended conformation in ATP-binding site, and they share a high consistence between the crystal and grafted binding modes in the site, with only a moderate displacement between core rings and a slight variation in side-chain moieties of different modes, indicating the rationality that same inhibitors bind similarly to different kinases, in particular those have high conservation.

\section{A systematic interaction spectrum for off-target inhibitors against MAPK kinases}

The complex structures of 18 off-target inhibitors with 10 mouse MAPK kinases were either solved by X-ray crystallography or modeled with inhibitor grafting and molecular docking, totally resulting in 180 inhibitor-kinase pairs, which were then subjected to MD simulations for conformational equilibrium and snapshot collection. Based on the collected snapshots the binding affinity score (DG) was calculated for each complex pair and, together, visualized as a heat map in Figure 4. The DG represents free energy change upon inhibitor binding to kinase (Tian et al. et al. 2011, 2014), and its negative and positive values indicate stabilization and destabilization of the binding, respectively (DG values are tabulated in Supplementary Material, Table S1).

As can be seen, a majority of inhibitor-kinase pairs exhibit a modest or low affinity (DG $>-10 \mathrm{kcal} / \mathrm{mol}$ ), albeit all of them seem to spontaneously interact with each other (DG $<0$ ), suggesting that these off-target inhibitors are generally not the good binders of mouse MAPK kinases, and they are able to inhibit the kinases potently and should have a low adverse effect on bone system. However, several inhibitor-kinase pairs were predicted to have a high affinity (DG $<-10 \mathrm{kcal} / \mathrm{mol}$ ) that may cause the unexpected targeting of these inhibitors to MAPK kinases in mouse osteoblasts. In addition, the inhibitor binding profile displays a consistence within the same kinase subgroups. For example, the PF04691502 can interact effectively with all the three kinases Jnk1, Jnk2 and Jnk3 in the Jnk subgroup (DG $<-9 \mathrm{kcal} /$ $\mathrm{mol}$ ), while the Dasatinib exhibits high binding potency for three members $\mathrm{p} 38 \mathrm{\alpha}, \mathrm{p} 38 \beta$ and $\mathrm{p} 38 \gamma$ of the p38 subgroup $(\mathrm{DG}<-10 \mathrm{kcal} / \mathrm{mol})$. Interestingly, the Dasatinib has also been previously reported to influence the activation of $\mathrm{p} 38$ pathway (Dumka et al. 2009); this can be well reflected in the interaction spectrum. Here, totally 14 inhibitor-kinase pairs with high predicted affinity (DG $<-10 \mathrm{kcal} / \mathrm{mol}$ ) are derived from the interaction spectrum and listed in Table 3; they are considered as the potential unexpected interactions of off-target inhibitors with mouse MAPK kinases.

\section{Cell-based and cell-free assays of unexpected inhibitor- $k i$ - nase interactions}

The unexpected targeting of MAPK pathway with off-target kinase inhibitors can address essential effects on the growth, proliferation and differentiation of osteoblasts (Greenblatt et al. 2013). The effects can be reflected at cellular level as dose-dependent cytotoxicity, which is the untargeted result of targeted therapies with off-target inhibitors. The mouse MC3T3-E1 osteoblastic cell line was treated separately with five compounds Nilotinib, Dasatinib, Bosutinib, SP600125

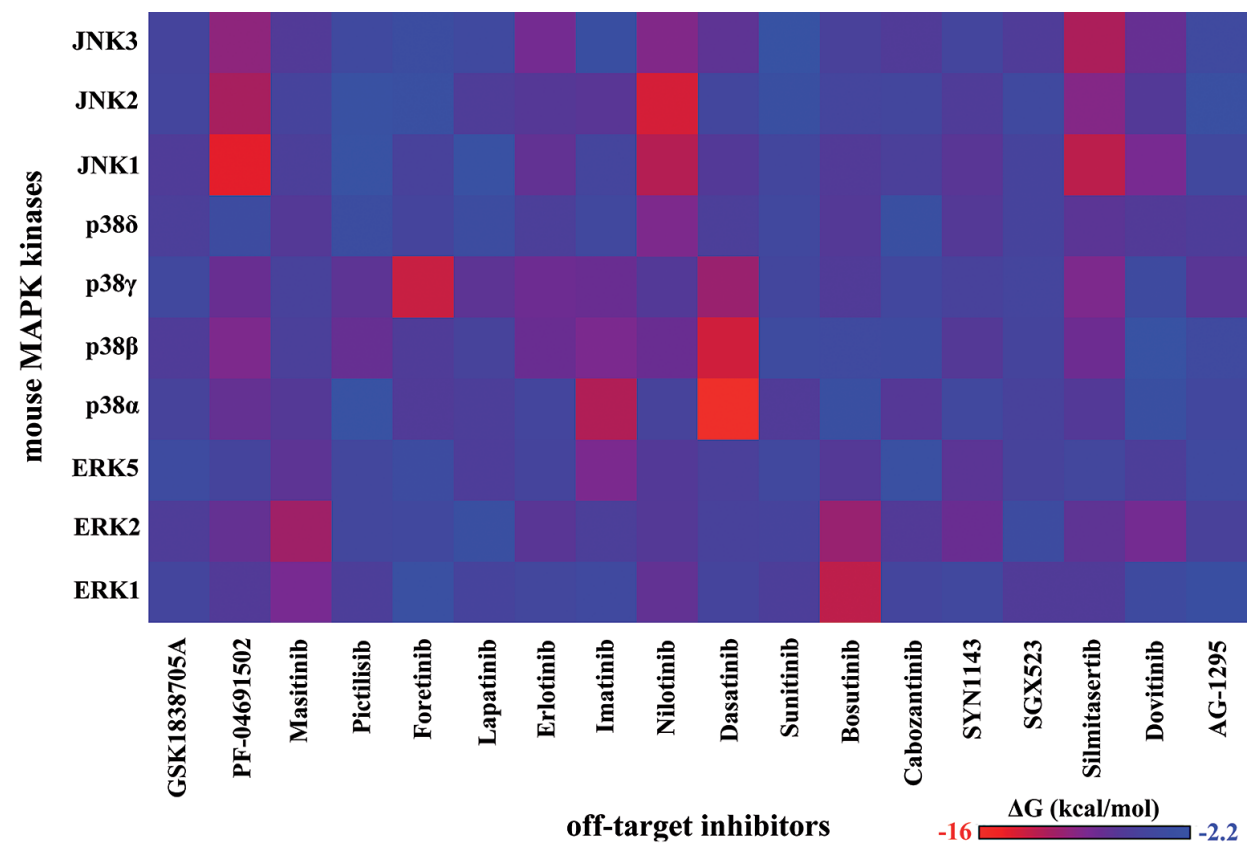

Figure 4. A systematic interaction spectrum for 18 off-target inhibitors against 10 mouse MAPK kinases. The plot is characterized by binding affinity score $(\Delta G)$. 
Table 3. The 14 inhibitor-kinase pairs predicted as potential unexpected interactions in bone system

\begin{tabular}{|c|c|}
\hline Inhibitor-kinase pair & $\begin{array}{c}\Delta G \\
\mathrm{kcal} / \mathrm{mol}\end{array}$ \\
\hline PF-04691502-Jnk1 & -13.8 \\
\hline PF-04691502-Jnk2 & -11.1 \\
\hline Masitinib-Erk2 & -10.8 \\
\hline Foretinib-p38 $\gamma$ & -12.6 \\
\hline Imatinib-p38a & -10.6 \\
\hline Nilotinib-Jnk1 & -10.8 \\
\hline Nilotinib-Jnk2 & -13.1 \\
\hline Dasatinib-p38a & -15.7 \\
\hline Dasatinib-p38 $\beta$ & -12.9 \\
\hline Dasatinib-p38 $\gamma$ & -10.4 \\
\hline Bosutinib-Erk1 & -12.2 \\
\hline Bosutinib-Erk2 & -10.3 \\
\hline Silmitasertib-Jnk1 & -12.1 \\
\hline Silmitasertib-Jnk3 & -11.4 \\
\hline
\end{tabular}

and SB203580; the former three were predicted to have potential unexpected interactions with Jnk, p38 and Erk subgroups, respectively, in terms of the inhibitor-kinase interaction spectrum, while the latter two are known MAPK inhibitors that were used as positive controls in this study. As seen in Figure 5, the two positive controls SP600125 and SB203580 have high cytotoxic effect on MC3T3-E1, which can block the cell growth at a low concentration. Interestingly, the off-target inhibitor Dasatinib also exhibits a similar cytotoxicity profile with these positive controls, which can considerably reduce MC3T3-E1 viability with a low concentration, indicating that the Dasatinib is a potent inhibitor of MAPK pathway by targeting p38 subgroup, especially the $\mathrm{p} 38 \mathrm{a}$ kinase $(\mathrm{DG}=-15.7 \mathrm{kcal} / \mathrm{mol})$. The Nilotinib also exhibits a moderate cytotoxic effect on MC3T3-E1, which is roughly close to that of pan-Jnk inhibitor SP600125, albeit the former seems to be less effective than the latter. In addition, the Bosutinib was determined to have a weak potency that can influence the cell viability only at a high concentration $(>100 \mu \mathrm{M})$.

Next, three compounds Dasatinib, SB203580 and Bosutinib were chosen to determine their inhibitory activity against mouse p38a kinase domain at molecular level (Table 4). The Dasatinib was supposed as a potential p38a inhibitor with a high binding affinity $(\mathrm{DG}=-15.7 \mathrm{kcal} / \mathrm{mol})$, which has a similar cytotoxicity profile with the known p38a inhibitor SB203580 on mouse MC3T3-E1 cell line. In fact, the Dasatinib has been previously observed to dysregulate bone remodeling through disruption of osteoclasts in vivo, which

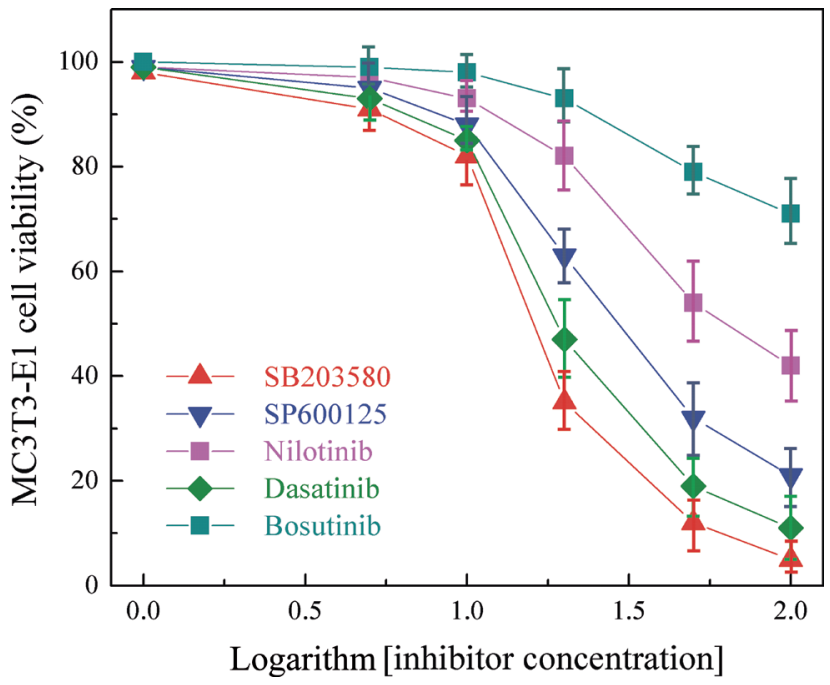

Figure 5. Cytotoxic effects of three potential off-target inhibitors Nilotinib, Dasatinib and Bosutinib as well as two positive controls SP600125 and SB203580 on MC3T3-E1 osteoblastic cells. The error bar is derived from triplicate assays.

increased trabecular bone volume by inhibiting osteoclast activity (Vandyke et al. 2010). In addition, although the Bosutinib was predicted as potent binder of Erk1/2 kinases, this inhibitor was estimated to have only a very low activity for $\mathrm{p} 38 \mathrm{a}$ kinase $(\mathrm{DG}=-3.0 \mathrm{kcal} / \mathrm{mol})$ and was measured to possess a moderate cytotoxicity for MC3T3-E1. Consequently, the positive control SB203580 was determined to have a high potency against mouse $\mathrm{p} 38 \alpha\left(\mathrm{IC}_{50}=1.8 \mu \mathrm{M}\right)$, which is basically in line with that against human $\mathrm{p} 38 \mathrm{a}$ kinase $\left(\mathrm{IC}_{50}=0.3-0.5 \mu \mathrm{M}\right)$ (Lali et al. 2000). Analogous to the positive control, Dasatinib was also determined to have a strong potency, which can inhibit the mouse p38a kinase with $\mathrm{IC}_{50}$ value of $5.4 \mu \mathrm{M}$. In contract, no activity was found for the negative control Bosutinib. Overall, the experimental tests are well in line with computational findings.

Table 4. Binding score and inhibitory activity of SB203580, Bosutinib and Dasatinib against mouse p38a kinase

\begin{tabular}{lccc}
\hline Inhibitor & Description & $\begin{array}{c}\mathrm{IC}_{50} \\
(\mu \mathrm{M})^{\mathrm{a}}\end{array}$ & $\begin{array}{c}\mathrm{DG} \\
(\mathrm{kcal} / \mathrm{mol})\end{array}$ \\
\hline SB203580 & positive control & $1.8 \pm 0 \cdot 3 \mathrm{~b}$ & -16.2 \\
Bosutinib & $\begin{array}{c}\text { negative control } \\
\text { predicted } 38 \mathrm{a} \\
\text { no activity }\end{array}$ & -3.0 \\
Dasatinib & $5.4 \pm 1.6$ & -15.7 \\
\hline
\end{tabular}

$\bar{a}$ measured in triplicate. ${ }^{\mathrm{b}} \mathrm{IC}_{50}=0.3-0.5 \mu \mathrm{M}$ for human $\mathrm{p} 38 \mathrm{a}$ kinase (Lali et al. 2000). 

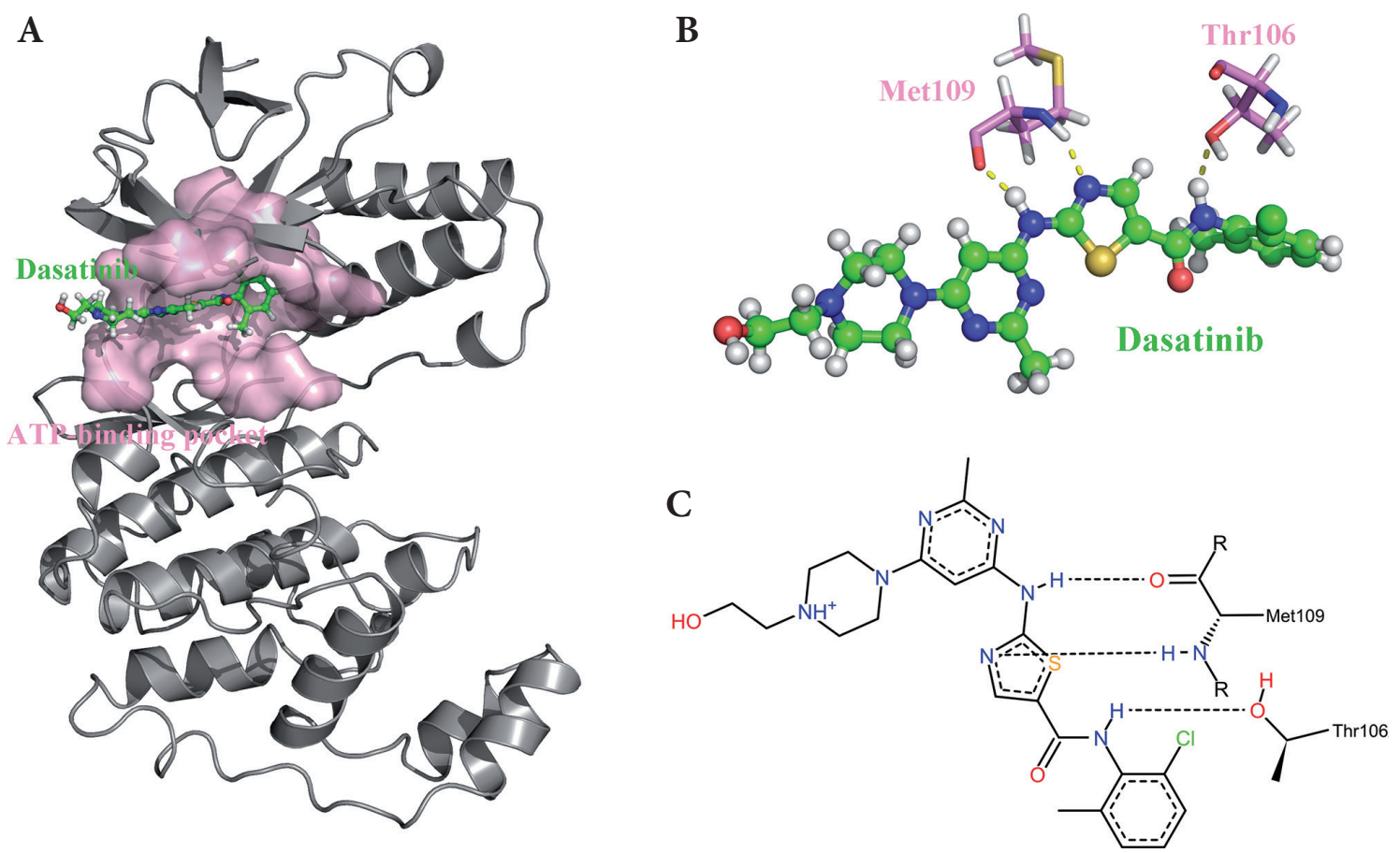

Figure 6. A. The complex structure of mouse p38a kinase domain with off-target inhibitor Dasatinib.B. Zoom up of hydrogen-bonding residues with Dasatinib. C. Schematic representation of three hydrogen bonds across the inhibitor-kinase complex interface generated using PoseView program (Stierand et al. 2006).

The complex structure of mouse p38a kinase with its potential inhibitor Dasatinib is shown in Figure 6. The inhibitor ligand adopts an extended conformation in the ATP-binding pocket of the mouse kinase, which exhibits a similar binding mode with that of human $\mathrm{p} 38 \alpha$ kinase (PDB: 3lfa). Based on the structure the inhibitor molecule was identified to form three hydrogen bonds with the kinase residues Thr106 and Met109 by using PoseView program (Stierand et al. 2006), which should define the strong selectivity and specificity in inhibitor-kinase recognition, while a number of nonspecific chemical forces such as such as hydrophobic interactions and van der Waals contacts can also observed at the complex interface, which are considered to stabilize the inhibitor-kinase interaction (Luo et al. 2015). Overall, the Dasatinib is suggested as a good binder and a potent inhibitor of its noncognate p38a kinase, which can be either used to investigate its untargeted side effects on bone system or exploited as a new cognate p38a inhibitor for targeted therapy.

Acknowledgements. This work was supported by the Science and Technology Support Project of Zhangiiagang Science and Technology Bureau (No. Zks1741).

Conflicts of interest. No potential conflicts of interest.

\section{References}

Altschul S, Gish W, Miller W, Myers E, Lipman D (1990): Basic local alignment search tool. J. Mol. Biol. 215, 403-410 https://doi.org/10.1016/S0022-2836(05)80360-2

Alemán JO, Farooki A, Girotra M (2014): Effects of tyrosine kinase inhibition on bone metabolism: untargeted consequences of targeted therapies. Endocr. Relat. Cancer 21, R247-259 https://doi.org/10.1530/ERC-12-0400

Anastassiadis T, Deacon SW, Devarajan K, Ma H, Peterson JR (2011): Comprehensive assay of kinase catalytic activity reveals features of kinase inhibitor selectivity. Nat. Biotechnol. 29, 1039-1045 https://doi.org/10.1038/nbt.2017

Bai Z, Hou S, Zhang S, Li Z, Zhou P (2017): Targeting self-binding peptides as a novel strategy to regulate protein activity and function: a case study on the proto-oncogene tyrosine protein kinase c-Src. J. Chem. Inf. Model. 57, 835-845 https://doi.org/10.1021/acs.jcim.6b00673

Bao NR, Lu M, Bin FW, Chang ZY, Meng J, Zhou LW, Guo T, Zhao JN (2013): Systematic screen with kinases inhibitors reveals kinases play distinct roles in growth of osteoprogenitor cells. Int. J. Clin. Exp. Pathol. 6, 2082-2091

Bayly CI, Cieplak P, Cornell WD, Kollman PA (1993): A wellbehaved electrostatic potential based method using charge restraints for deriving atomic charges - the RESP model. J. Phys. Chem. 97, 10269-10280 https://doi.org/10.1021/j100142a004 
Berman HM, Westbrook J, Feng Z, Gilliland G, Bhat TN, Weissig $\mathrm{H}$, Shindyalov IN, Bourne PE (2000): The protein data bank. Nucleic Acids Res. 28, 235-242

https://doi.org/10.1093/nar/28.1.235

Berman E, Nicolaides M, Maki RG, Fleisher M, Chanel S, Scheu K, Wilson BA, Heller G, Sauter NP (2006): Altered bone and mineral metabolism in patients receiving imatinib mesylate. N. Engl. J. Med. 354, 2006-2013 https://doi.org/10.1056/NEJMoa051140

Bhullar KS, Lagarón NO, McGowan EM, Parmar I, Jha A, Hubbard BP, Rupasinghe HPV (2018): Kinase-targeted cancer therapies: progress, challenges and future directions. Mol. Cancer 17, 48 https://doi.org/10.1186/s12943-018-0804-2

Brunello A, Saia G, Bedogni A, Scaglione D, Basso U (2009): Worsening of osteonecrosis of the jaw during treatment with sunitinib in a patient with metastatic renal cell carcinoma. Bone 44, 173-175 https://doi.org/10.1016/j.bone.2008.08.132

Case DA, Cheatham TE 3rd, Darden T, Gohlke H, Luo R, Merz KM Jr, Onufriev A, Simmerling C, Wang B, Woods RJ (2005): The amber biomolecular simulation programs. J. Comput. Chem. 26, $1668-1688$ https://doi.org/10.1002/jcc.20290

Cargnello M, Roux PP (2011): Activation and function of the MAPKs and their substrates, the MAPK-activated protein kinases. Microbiol. Mol. Biol. Rev. 75, 50-83 https://doi.org/10.1128/MMBR.00031-10

Cui YH, Chen J, Xu T, Tian HL (2015): Structure-based grafting and identification of kinase-inhibitors to target mTOR signaling pathway as potential therapeutics for glioblastoma. Comput. Biol. Chem. 54, 57-65 https://doi.org/10.1016/j.compbiolchem.2015.01.001

Dai J, Zhang H, Karatsinides A, Keller JM, Kozloff KM, Aftab DT, Schimmoller F, Keller ET (2014): Cabozantinib inhibits prostate cancer growth and prevents tumor-induced bone lesions. Clin. Cancer Res. 20, 617-630 https://doi.org/10.1158/1078-0432.CCR-13-0839

Darden T, York D, Pedersen L (1993): Particale mesh Ewald and $\mathrm{N} \cdot \log (\mathrm{N})$ method for Ewald sums in large systems. J. Chem. Phys. 98, 10089-10092 https://doi.org/10.1063/1.464397

De Moliner E, Brown NR, Johnson LN (2003): Alternative binding modes of an inhibitor to two different kinases. Eur. J. Biochem. $270,3174-3181$ https://doi.org/10.1046/j.1432-1033.2003.03697.x

D`Oronzo S, Stucci S, Tucci M, Silvestris F (2015): Cancer treatment-induced bone loss (CTIBL): pathogenesis and clinical implications. Cancer Treat. Rev. 41, 798-808 https://doi.org/10.1016/j.ctrv.2015.09.003

Dumka D, Puri P, Carayol N, Lumby C, Balachandran H, Schuster K, Verma AK, Terada LS, Platanias LC, Parmar S (2009): Activation of the p38 Map kinase pathway is essential for the antileukemic effects of dasatinib. Leuk. Lymphoma 50, 2017-2029 https://doi.org/10.3109/10428190903147637

Ge C, Xiao G, Jiang D, Franceschi RT (2007): Critical role of the extracellular signal-regulated kinase-MAPK pathway in osteoblast differentiation and skeletal development. J. Cell. Biol. 176, 709-718 https://doi.org/10.1083/jcb.200610046

Geourjon C, Combet C, Blanchet C, Deléage G (2001): Identification of related proteins with weak sequence identity using secondary structure information. Protein Sci. 10, 788-797 https://doi.org/10.1110/ps.30001

Gouet P, Robert X, Courcelle E (2003): ESPript/ENDscript: Extracting and rendering sequence and $3 \mathrm{D}$ information from atomic structures of proteins. Nucleic Acids Res. 31, 3320-3323 https://doi.org/10.1093/nar/gkg556

Greenblatt MB, Shim JH, Zou W, Sitara D, Schweitzer M, Hu D, Lotinun S, Sano Y, Baron R, Park JM, et al. (2010): The p38 MAPK pathway is essential for skeletogenesis and bone homeostasis in mice. J. Clin. Invest. 120, 2457-2473 https://doi.org/10.1172/JCI42285

Greenblatt MB, Shim JH, Glimcher LH (2013): Mitogen-activated protein kinase pathways in osteoblasts. Annu. Rev. Cell. Dev. Biol. 29, 63-79 https://doi.org/10.1146/annurev-cellbio-101512-122347

Hove T, van den Blink B, Pronk I, Drillenburg P, Peppelenbosch MP, van Deventer SJ (2002): Dichotomal role of inhibition of p38 MAPK with SB 203580 in experimental colitis. Gut 50, 507-512 https://doi.org/10.1136/gut.50.4.507

Hu Y, Chan E, Wang SX, Li B (2003): Activation of p38 mitogenactivated protein kinase is required for osteoblast differentiation. Endocrinology 144, 2068-2074 https://doi.org/10.1210/en.2002-220863

Karahashi H, Nagata K, Ishii K, Amano F (2000): A selective inhibitor of p38 MAP kinase, SB202190, induced apoptotic cell death of a lipopolysaccharide-treated macrophage-like cell line, J774.1. Biochim. Biophys. Acta 1502, 207-223 https://doi.org/10.1016/S0925-4439(00)00045-4

Kim JW, Lee MN, Jeong BC, Oh SH, Kook MS, Koh JT (2017): Chemical inhibitors of c-Met receptor tyrosine kinase stimulate osteoblast differentiation and bone regeneration. Eur. J. Pharmacol. 806, 10-17 https://doi.org/10.1016/j.ejphar.2017.03.032

Lali FV, Hunt AE, Turner SJ, Foxwell BM (2000): The pyridinyl imidazole inhibitor SB203580 blocks phosphoinositide-dependent protein kinase activity, protein kinase $\mathrm{B}$ phosphorylation, and retinoblastoma hyperphosphorylation in interleukin2-stimulated T cells independently of p38 mitogen-activated protein kinase. J. Biol. Chem. 275, 7395-7402 https://doi.org/10.1074/jbc.275.10.7395

Lefloch R, Pouysségur J, Lenormand P (2008): Single and combined silencing of ERK1 and ERK2 reveals their positive contribution to growth signaling depending on their expression levels. Mol. Cell. Biol. 28, 511-527 https://doi.org/10.1128/MCB.00800-07

Luo H, Du T, Zhou P, Yang L, Mei H, Ng H, Zhang W, Shu M, Tong W, Shi L, Mendrick DL, Hong H (2015): Molecular docking to identify associations between drugs and class I human leukocyte antigens for predicting idiosyncratic drug reactions. Comb. Chem. High. Throughput. Screen. 18, 296-304 https://doi.org/10.2174/1386207318666150305144015

Mackay K, Mochly-Rosen D (1999): An inhibitor of p38 mitogenactivated protein kinase protects neonatal cardiac myocytes from ischemia. J. Biol. Chem. 274, 6272-6279 https://doi.org/10.1074/jbc.274.10.6272 
Marti-Renom MA, Stuart AC, Fiser A, Sanchez R, Melo F, Sali A (2000): Comparative protein structure modeling of genes and genomes. Annu. Rev. Biophys. Biomol. Struct. 29, 291-325

https://doi.org/10.1146/annurev.biophys.29.1.291

Meng L, Huang Z (2018): In silico-in vitro discovery of untargeted kinase-inhibitor interactions from kinase-targeted therapies: a case study on the cancer signaling pathway. Comput. Biol. Chem. 75, 196-204 https://doi.org/10.1016/j.compbiolchem.2018.05.012

Morris GM, Huey R, Lindstrom W, Sanner MF, Belew RK, Goodsell DS, Olson AJ (2009): Autodock4 and AutoDockTools4: automated docking with selective receptor flexibility. J. Comput. Chem. 16, 2785-2791 https://doi.org/10.1002/jcc.21256

Nishimoto S, Nishida E (2006): MAPK signalling: ERK5 versus ERK1/2. EMBO Rep. 7, 782-786 https://doi.org/10.1038/sj.embor.7400755

Qiao X, Nie Y, Ma Y, Chen Y, Cheng R, Yin W, Hu Y, Xu W, Xu L (2016): Irisin promotes osteoblast proliferation and differentiation via activating the MAP kinase signaling pathways. Sci. Rep. 6, 18732 https://doi.org/10.1038/srep18732

O'Sullivan S, Lin JM, Watson M, Callon K, Tong PC, Naot D, Horne A, Aati O, Porteous F, Gamble G, Cornish J, Browett P, Grey A (2011): The skeletal effects of the tyrosine kinase inhibitor nilotinib. Bone 49, 281-289 https://doi.org/10.1016/j.bone.2011.04.014

Rodríguez-Carballo E, Gámez B, Ventura F (2016): p38 MAPK signaling in osteoblast differentiation. Front. Cell. Dev. Biol. 4, 40 https://doi.org/10.3389/fcell.2016.00040

Ryckaert JP, Ciccotti G, Berendsen HJC (1977): Numerical integration of the cartesian equations of motion of a system with constraints: molecular dynamics of $\mathrm{n}$-alkanes. J. Comput. Phys. 23, 327-341 https://doi.org/10.1016/0021-9991(77)90098-5

Ryu J, Lee M, Cha J, Laskowski RA, Ryu SE, Kim DS (2016): BetaSCPWeb: side-chain prediction for protein structures using Voronoi diagrams and geometry prioritization. Nucleic Acids Res. 44, W416-423

https://doi.org/10.1093/nar/gkw368

Son Y, Cheong YK, Kim NH, Chung HT, Kang DG, Pae HO (2011): Mitogen-activated protein kinases and reactive oxygen species: how can ROS activate MAPK pathways? J. Signal. Transduct. 2011, 792639 https://doi.org/10.1155/2011/792639

Shen X, Chen B, Ma Z, Xie B, Cao X, Yang T, Zhao Y, Qin J, Li J, Cao F, Chen X (2016): A systematic analysis of the resistance and sensitivity of HER2YVMA receptor tyrosine kinase mutant to tyrosine kinase inhibitors in HER2-positive lung cancer. J. Recept. Signal. Transduct. Res. 36, 89-97 https://doi.org/10.3109/10799893.2015.1049361

Stierand K, Maass PC, Rarey M (2006): Molecular complexes at a glance: automated generation of two-dimensional complex diagrams. Bioinformatics 22, 1710-1716 https://doi.org/10.1093/bioinformatics/btl150

Tauer JT, Hofbauer LC, Jung R, Erben RG, Suttorp M (2013): Micro-osmotic pumps for continuous release of the tyrosine kinase inhibitor bosutinib in juvenile rats and its impact on bone growth. Med. Sci. Monit. Basic Res. 19, 274-278 https://doi.org/10.12659/MSMBR.889518

Tian F, Lv Y, Zhou P, Yang L (2011): Characterization of PDZ domain-peptide interactions using an integrated protocol of QM/MM, PB/SA, and CFEA analyses. J. Comput. Aided Mol. Des. 25, 947-958 https://doi.org/10.1007/s10822-011-9474-5

Tian F, Yang C, Wang C, Guo T, Zhou P (2014): Mutatomics analysis of the systematic thermostability profile of Bacillus subtilis lipase A. J. Mol. Model. 20, 2257 https://doi.org/10.1007/s00894-014-2257-x

Thouverey C, Caverzasio J (2015): Focus on the p38 MAPK signaling pathway in bone development and maintenance. Bonekey. Rep. 4, 711 https://doi.org/10.1038/bonekey.2015.80

UniProt C (2015): UniProt: a hub for protein information. Nucleic Acids Res. 43, D204-212 https://doi.org/10.1093/nar/gku989

Vandyke K, Dewar AL, Diamond P, Fitter S, Schultz CG, Sims NA, Zannettino AC (2010): The tyrosine kinase inhibitor dasatinib dysregulates bone remodeling through inhibition of osteoclasts in vivo. J. Bone Miner. Res. 25, 1759-1770 https://doi.org/10.1002/jbmr.85

Vulpetti A, Pevarello P (2005): An analysis of the binding modes of ATP-competitive CDK2 inhibitors as revealed by X-ray structures of protein-inhibitor complexes. Curr. Med. Chem. Anticancer Agents 5, 561-573 https://doi.org/10.2174/1568011054866928

Wang J, Wolf RM, Caldwell JW, Kollman PA, Case DA (2004): Development and testing of a general amber force field. J. Comput. Chem. 25, 1157-1174 https://doi.org/10.1002/jcc.20035

Yang C, Wang C, Zhang S, Huang J, Zhou P (2015a): Structural and energetic insights into the intermolecular interaction among human leukocyte antigens, clinical hypersensitive drugs and antigenic peptides. Mol. Simul. 41, 741-751 https://doi.org/10.1080/08927022.2014.929127

Yang C, Zhang S, He P, Wang C, Huang J, Zhou P (2015b): Self-binding peptides: folding or binding? J. Chem. Inf. Model. 55, 329-342 https://doi.org/10.1021/ci500522v

Yang C, Zhang S, Bai Z, Hou S, Wu D, Huang J, Zhou P (2016): A two-step binding mechanism for the self-binding peptide recognition of target domains. Mol. Biosyst. 12, 1201-1213 https://doi.org/10.1039/C5MB00800J

Yamamoto N, Otsuka T, Kuroyanagi G, Kondo A, Kainuma S, Nakakami A, Matsushima-Nishiwaki R, Kozawa O, Tokuda H (2015): Resveratrol reduces prostaglandin E1-stimulated osteoprotegerin synthesis in osteoblasts: suppression of stressactivated protein kinase/c-Jun N-terminal kinase. Prostaglandins Other. Lipid. Mediat. 116, 57-63 https://doi.org/10.1016/j.prostaglandins.2015.01.003

Yu H, Zhou P, Deng M, Shang Z (2014): Indirect readout in protein-peptide recognition: a different story from classical biomolecular recognition. J. Chem. Inf. Model. 54, 2022-2032 https://doi.org/10.1021/ci5000246

Zhan C, Li S, Zhong Q, Zhou D (2015): Structure-based grafting, mutation, and optimization of peptide inhibitors to fit in the 
active pocket of human secreted phospholipase A2: find new use of old Peptide agents with anti-inflammatory activity. Chem. Biol. Drug Des. 85, 418-426 https://doi.org/10.1111/cbdd.12424

Zhou P, Yang C, Ren Y, Wang C, Tian F (2013a): What are the ideal properties for functional food peptides with antihypertensive effect? A computational peptidology approach. Food. Chem. 141, 2967-2973 https://doi.org/10.1016/j.foodchem.2013.05.140

Zhou P, Wang C, Tian F, Ren Y, Yang C, Huang J (2013b): Biomacromolecular quantitative structure-activity relationship (BioQSAR): a proof-of-concept study on the modeling, prediction and interpretation of protein-protein binding affinity. J. Comput. Aided Mol. Des. 27, 67-78 https://doi.org/10.1007/s10822-012-9625-3

Zhou P, Zhang S, Wang Y, Yang C, Huang J (2016): Structural modeling of HLA-B ${ }^{\star} 1502 /$ peptide/carbamazepine/T-cell receptor complex architecture: implication for the molecular mechanism of carbamazepine-induced Stevens-Johnson syndrome/toxic epidermal necrolysis. J. Biomol. Struct. Dyn. 34, 1806-1817 https://doi.org/10.1080/07391102.2015.1092476

Zhou P, Hou S, Bai Z, Li Z, Wang H, Chen Z, Meng Y (2018): Disrupting the intramolecular interaction between protooncogene c-Src SH3 domain and its self-binding peptide PPII with rationally designed peptide ligands. Artif. Cells Nanomed. Biotechnol. 46, 1122-1131 https://doi.org/10.1080/21691401.2017.1360327

Zhang YY, Cui YZ, Luan J, Zhou XY, Zhang GL, Han JX (2012): Platelet-derived growth factor receptor kinase inhibitor AG1295 promotes osteoblast differentiation in MC3T3-E1 cells via the Erk pathway. Biosci. Trends 6, 130-135 https://doi.org/10.5582/bst.2012.v6.3.130

Received: April 1, 2018

Final version accepted: August 9, 2018

First published online: January 18, 2019 